Article

\title{
Variability of Major Phenyletanes and Phenylpropanoids in 16-Year-Old Rhodiola rosea L. Clones in Norway
}

\author{
Abdelhameed Elameen ${ }^{1, *(\mathbb{D})}$, Vera M. Kosman ${ }^{2}$, Mette Thomsen ${ }^{3}$, Olga N. Pozharitskaya ${ }^{4}(\mathbb{D}$ \\ and Alexander N. Shikov ${ }^{5}$ \\ 1 NIBIO, Norwegian Institute for Bioeconomy Research, Høghskoleveien 7, N-1431 Ås, Norway \\ 2 St. Petersburg Institute of Pharmacy, Leningrad Region, Vsevolozhsky District, P 245188663 Kuzmolovo, Russia; \\ kosmanvm@mail.ru \\ 3 NIBIO, Norwegian Institute for Bioeconomy Research, Øst Apelsvoll, 2849 Kapp, Norway; \\ mette.thomsen@nibio.no \\ 4 Murmansk Marine Biological Institute of the Russian Academy of Sciences (MMBI RAS), Vladimirskaya, 17, \\ 183010 Murmansk, Russia; olgapozhar@mail.ru \\ 5 St. Petersburg State Chemical Pharmaceutical University, Prof. Popov, 14, 197376 Saint-Petersburg, Russia; \\ spb.pharmacy@gmail.com \\ * Correspondence: abdelhameed.elameen@nibio.no; Tel.: +479-020-0875
}

Academic Editors: Francesco Cacciola and Lillian Barros

Received: 17 June 2020; Accepted: 28 July 2020; Published: 30 July 2020

\begin{abstract}
Rhodiola rosea L. (roseroot) is an adaptogen plant belonging to the Crassulaceae family. The broad spectrum of biological activity of $R$. rosea is attributed to its major phenyletanes and phenylpropanoids: rosavin, salidroside, rosin, cinnamyl alcohol, and tyrosol. In this study, we compared the content of phenyletanes and phenylpropanoids in rhizomes of $R$. rosea from the Norwegian germplasm collection collected in 2004 and in 2017. In general, the content of these bioactive compounds in 2017 was significantly higher than that observed in 2004 . The freeze-drying method increased the concentration of all phenyletanes and phenylpropanoids in rhizomes compared with conventional drying at $70{ }^{\circ} \mathrm{C}$. As far as we know, the content of salidroside $\left(51.0 \mathrm{mg} \mathrm{g}^{-1}\right)$ observed in this study is the highest ever detected in Rhodiola spp. Long-term vegetative propagation and high genetic diversity of $R$. rosea together with the freeze-drying method may have led to the high content of the bioactive compounds observed in the current study.
\end{abstract}

Keywords: bioactive compounds; cinnamyl alcohol; freeze-drying; HPLC; Rhodiola rosea; rosavin; rosin; salidroside; tyrosol

\section{Introduction}

Rhodiola rosea L. (accepted name Sedum roseum (L.) Scop. according to www.theplantlist.org), also known as roseroot, artic-root, or golden root, is an adaptogen plant belonging to the Crassulaceae family [1-5]. R. rosea is distributed in China, Russia, Central, Northern Europe, and North America. In Scandinavia, $R$. rosea has been used as a traditional adaptogen agent for a long time, and the Vikings used it to enhance their physical performance, strength, and endurance [6]. Currently, many studies claim that $R$. rosea extracts and its bioactive compounds have antioxidant and antibacterial effects and therapeutic applications including for brain diseases and cancer therapy [3,7-13].

$R$. rosea rhizomes are mostly collected from natural habitats, and due to the intensive collection, natural populations are highly threatened [14,15]. $R$. rosea has become a threatened plant species in many countries [15-18], and in Bulgaria the species is listed on the red list as an endangered plant species [19]. The intensive harvesting of the natural populations as a consequence of the rapidly 
growing demand and the high price of the raw material resulted in increased pressure on the natural $R$. rosea habitats $[15,20]$. Therefore, the introduction and cultivation of $R$. rosea is an important issue to preserve and to maintain the genetic diversity of the species. Norway is one of the countries in Europe where $R$. rosea is most abundant and distributed all over the country and is known to have high genetic diversity [21,22]. The Norwegian germplasm collection of $R$. rosea was established in 2001 and originated from different counties, was vegetatively propagated, and was grown under uniform environmental conditions for 19 growing seasons [21].

Among more than 150 bioactive compounds identified in $R$. rosea [3], the major compounds with important pharmacological values are salidroside, tyrosol, rosavin, rosin, and cinnamyl alcohol, which belong to phenyletanes and phenylpropanoids [7,13,23-26]. The concentration of the bioactive compounds in $R$. rosea meeting the pharmacopeia requirement and the limited genetic resources of the species are the main challenges of meeting the demand of the global market $[20,21,26,27]$. Due to their bioactivity effects, salidroside and rosavin have been recommended to be used as markers for quality evaluation of $R$. rosea $[3,7,10,13,28,29]$. Thus, $R$. rosea extracts used in most clinical studies have been standardized to contain $0.8-1 \%$ salidroside and a minimum of $3 \%$ rosavin $[30,31]$. One challenging aspect is that salidroside and rosavin content in most $R$. rosea species is low [26]. Some studies were performed to increase the content of these important compounds using synthetic biology and other biotechnology methods $[32,33]$. The age of plants, method of drying plant material, and temperature could affect the yield of active compounds.

The objective of this study was to investigate the influence of long-term vegetative propagation on the production of the major phenyletanes and phenylpropanoids rosavin, salidroside, rosin, cinnamyl alcohol, and tyrosol by rhizomes of $R$. rosea. We also studied the impact of the freeze-drying method at $-130{ }^{\circ} \mathrm{C}$ versus conventional drying at $70{ }^{\circ} \mathrm{C}$ on the content of bioactive compounds. To achieve these goals, seven clones of $R$. rosea were studied.

\section{Results}

\subsection{Comparison of Phenyletanes and Phenylpropanoids Content in $R$. rosea Clones}

The amount of water lost using drying at $70{ }^{\circ} \mathrm{C}$ was between $74.19 \%$ and $78.28 \%$, while water lost using freeze-drying at $-130{ }^{\circ} \mathrm{C}$ was slightly higher and varied from $75.17 \%$ to $78.62 \%$ (the difference was not statistically significant, $p>0.05)$. The amount of water lost varied among $R$. rosea clones; clone M7 lost 75\% water content, while clone M6 lost up to 78\% (Table 1).

Table 1. The amount of water lost using freeze-drying at $-130{ }^{\circ} \mathrm{C}$ and drying at $70{ }^{\circ} \mathrm{C}$ in seven $R$. rosea clones cultivated in the germplasm collection in Norway since 2001 (mean \pm standard deviation).

\begin{tabular}{ccccccc}
\hline \multirow{2}{*}{ Clone Id } & \multicolumn{3}{c}{$\begin{array}{c}\text { Freeze-Drying } \\
\text { at } \mathbf{- 1 3 0}{ }^{\circ} \mathbf{C}\end{array}$} & \multicolumn{2}{c}{ Drying at 70 ${ }^{\circ} \mathbf{C}$} \\
\cline { 2 - 6 } & Fresh-Weight (g) & Dry Weight (g) & \% of Water Loss & Fresh-Weight (g) & Dry Weight (g) & \% of Water Loss \\
\hline M1 & $22.77 \pm 1.42$ & $5.21 \pm 0.31$ & 77.12 & $24.96 \pm 1.72$ & $5.88 \pm 0.64$ & 76.44 \\
M2 & $23.61 \pm 1.61$ & $5.37 \pm 0.28$ & 77.26 & $25.83 \pm 1.84$ & $6.08 \pm 0.92$ & 76.46 \\
M3 & $26.39 \pm 1.84$ & $6.31 \pm 0.42$ & 76.09 & $25.45 \pm 1.81$ & $6.22 \pm 0.81$ \\
M4 & $26.51 \pm 1.71$ & $6.12 \pm 0.38$ & 76.91 & $24.68 \pm 1.63$ & $5.98 \pm 0.73$ & 75.56 \\
M5 & $27.18 \pm 2.02$ & $6.53 \pm 0.61$ & 75.97 & $26.06 \pm 2.05$ & $6.44 \pm 1.02$ & 75.29 \\
M6 & $26.24 \pm 1.48$ & $5.61 \pm 0.84$ & 78.62 & $27.76 \pm 2.14$ & $6.03 \pm 1.11$ & 78.28 \\
M7 & $24.04 \pm 1.59$ & $5.97 \pm 0.76$ & 75.17 & $26.54 \pm 1.97$ & $6.85 \pm 0.94$ \\
\hline
\end{tabular}

HPLC is a widely used technique for quantifying salidroside, tyrosol, rosavin, rosin, and cinnamyl alcohol in $R$. rosea $[22,23,26,34,35]$. HPLC analyses showed the high content and large diversity in the concentration of phenyletanes and phenylpropanoids in the $R$. rosea clones collected in 2017 (Table 1). All five bioactive compounds were detected in all seven clones in 2004 and in 2017 (Figure 1). In 2004, the highest content of salidroside and cinnamyl alcohol was found in clone $\mathrm{M7}$, rosavin and rosin dominated in M5, while the maximal concentration of tyrosol was in clone M3. In 2017, the highest 
content of salidroside, rosavin, and rosin was observed in clone M7. Tyrosol was abundant in clone M3 as was cinnamyl alcohol in clone M4.
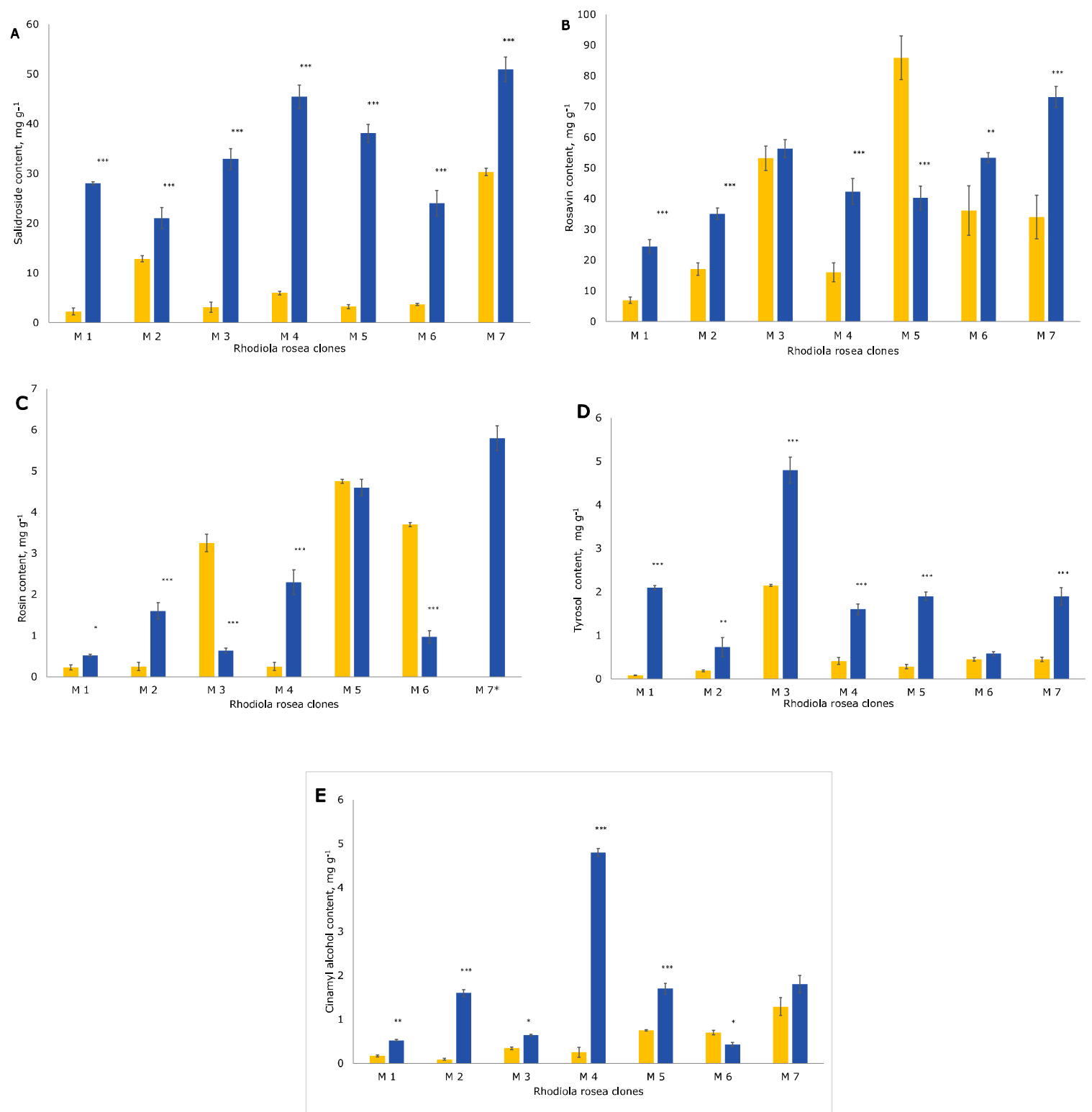

Figure 1. The concentration of the bioactive compounds in the seven clones (M1, M2, M3, M4, M5, M6, and M7) of R. rosea: (A) salidroside; (B) rosavin; (C) rosin; (D) tyrosol; and (E) cinnamyl alcohol; R. rosea analyzed in 2004 (orange color); produced in 2017 (blue color); mean concentration in $\mathrm{mg} \mathrm{g}^{-1} \pm$ standard deviation. Only results obtained using the freeze-drying method are presented in the figure. ${ }^{*}$ Rosin was not studied in 2004 in clone M7. ${ }^{*} p<0.05,{ }^{* *} p<0.01$, and ${ }^{* * *} p<0.001$ for all compounds compared to the samples analyzed in 2004.

Significantly increased content of bioactive compounds of $R$. rosea was achieved by using freeze-drying at $-130{ }^{\circ} \mathrm{C}$ rather than drying at $70^{\circ} \mathrm{C}$ (Table 2; Figure 2). 
Table 2. The concentration of rosavin, salidroside, rosin, cinnamyl alcohol, and tyrosol in $R$. rosea rhizomes (collected in 2017) after freeze-drying at $-130{ }^{\circ} \mathrm{C}$ and drying at $70{ }^{\circ} \mathrm{C}$ (mean in $\mathrm{mg} \mathrm{g}^{-1} \pm$ standard deviation).

\begin{tabular}{ccccc}
\hline \multirow{2}{*}{ Compound } & \multicolumn{2}{c}{ Freeze-Drying at $\mathbf{- 1 3 0}{ }^{\circ} \mathbf{C}$} & \multicolumn{2}{c}{ Drying at $\mathbf{7 0}{ }^{\circ} \mathbf{C}$} \\
\cline { 2 - 5 } & Minimum Level & Maximum Level & Minimum Level & Maximum Level \\
\hline Rosavin & $24.40 \pm 0.01^{*}$ & $73.12 \pm 1.24^{*}$ & $17.71 \pm 0.91$ & $54.0 \pm 3.31$ \\
Salidroside & $21.92 \pm 0.06^{* *}$ & $50.96 \pm 0.58^{* *}$ & $12.91 \pm 0.81$ & $38.72 \pm 1.82$ \\
Rosin & $0.52 \pm 0.02^{*}$ & $5.84 \pm 0.27$ & $0.17 \pm 0.03$ & $4.61 \pm 0.35$ \\
Cinnamyl alcohol & $0.43 \pm 0.01^{*}$ & $4.83 \pm 0.35^{* *}$ & $0.12 \pm 0.01$ & $1.62 \pm 0.24$ \\
Tyrosol & $0.58 \pm 0.01^{* * *}$ & $4.80 \pm 0.43^{*}$ & $0.23 \pm 0.03$ & $1.64 \pm 0.37$ \\
\hline
\end{tabular}

${ }^{*} p<0.05,{ }^{* *} p<0.01$, and ${ }^{* * *} p<0.001$ (freeze-drying at $-130{ }^{\circ} \mathrm{C}$ vs. drying at $70^{\circ} \mathrm{C}$ ).
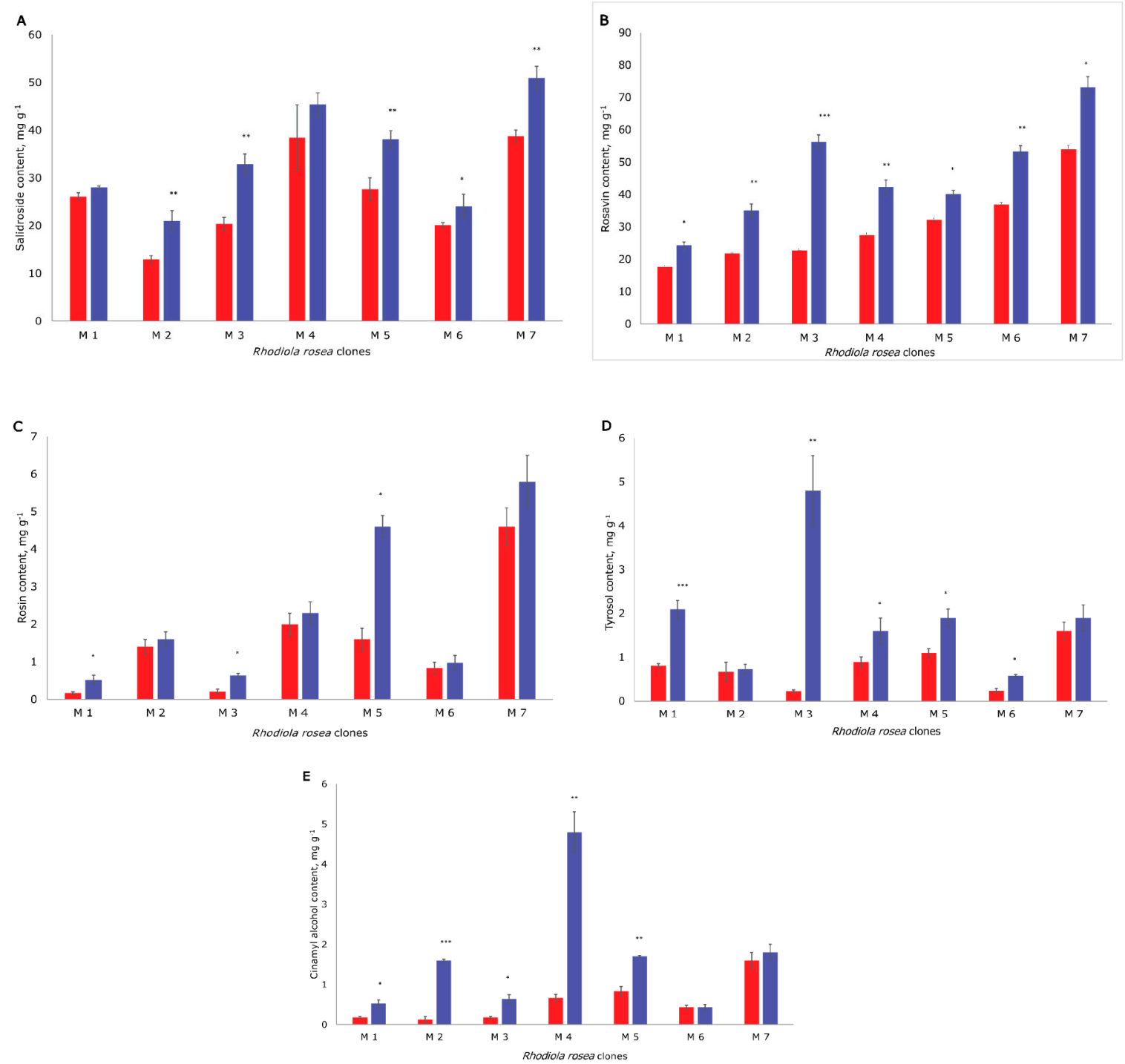

Figure 2. The concentration of the bioactive compounds in the seven clones (M1, M2, M3, M4, M5, M6, and M7) of $R$. rosea: (A) salidroside; (B) rosavin; (C) rosin; (D) tyrosol; and (E) cinnamyl alcohol; samples dried at $70{ }^{\circ} \mathrm{C}$ (red color); freeze-dried at $-130{ }^{\circ} \mathrm{C}$ (blue); mean concentration in $\mathrm{mg} \mathrm{g}^{-1} \pm$ standard deviation. ${ }^{*} p<0.05,{ }^{* *} p<0.01$, and ${ }^{* * *} p<0.001$ for all compounds compared to the samples dried at $70{ }^{\circ} \mathrm{C}$. 


\subsection{Statistical Analyses}

Pearson correlation analysis showed high significant correlations among the five compounds (rosavin, salidroside, rosin, cinnamyl alcohol, and tyrosol) measured in the $R$. rosea clones studied (Table 3). The highest significant correlation was found for the production of the rosavin and salidroside $(\mathrm{r}=0.9025 ; p \leq 0.001)$. The lowest correlation was found between salidroside and rosin (0.2648). Norwegian $R$. rosea clones contained high levels of bioactive compounds that exceeded the level required for $R$. rosea to be used for clinical treatment (Table 3).

Table 3. Pearson correlation coefficients ( $r$ ) for the correlation analysis between the concentration of bioactive compounds produced by R. rosea ${ }^{\#}$.

\begin{tabular}{cccccc}
\hline & Rosavin & Salidroside & Rosin & Cinnamyl Alcohol & Tyrosol \\
\hline Rosavin & 1.0000 & & & & \\
Salidroside & $0.9025^{* * *}$ & 1.00000 & & & \\
Rosin & $0.6431^{* *}$ & 0.2648 & 1.0000 & & \\
Cinnamyl alcohol & $0.4863^{*}$ & $0.5614^{*}$ & $0.7235^{* *}$ & 1.0000 & 1.0000 \\
Tyrosol & $0.6274^{* *}$ & $0.6349^{*}$ & $0.6184^{* *}$ & $0.4356^{*}$ & \\
\hline \# Results obtained using the freeze-drying method are presented in the table. ${ }^{*} p<0.05,{ }^{* *} p<0.01$, and ${ }^{* * *} p<0.001$.
\end{tabular}

Regression analysis showed no significant correlation between the results from a previously performed amplified fragment length polymorphism (AFLP) analysis [21] and the chemical composition of $R$. rosea clones in this study.

\section{Discussion}

In this study, we compared the content of phenyletanes and phenylpropanoids rosavin, salidroside, rosin, cinnamyl alcohol, and tyrosol in plants from the Norwegian germplasm collection of $R$. rosea first collected in 2001 and analyzed in 2004 [26] and collected and analyzed in 2017 (Figure 1). In general, the content of these bioactive compounds investigated in the current study was significantly higher than that observed in 2004. Rosavin content in clone M5 was lower. Rosin was increased in three clones (M1, M2, and M4) and was decreased in three clones (M3, M5, and M6) and was very high in clone 7, which was not studied previously [26].

Due to the bioactive effects, salidroside and rosavin have been proposed to be used as markers for quality evaluation of $R$. rosea $[28,29]$. The minimal concentration of salidroside and rosavin in high-quality rhizomes of $R$. rosea is recommended to be $0.8-1 \%$ and $3 \%$, respectively $[30,31,36]$. The levels of these two bioactive compounds were either low or absent in many samples of Rhodiola species market products $[37,38]$ reported in the literature (Table 4 ). The concentrations of bioactive compounds reported in Table 4 were calculated for absolute dry mass of rhizomes. Authors of some articles did not specify whether the concentrations of bioactive compounds were calculated for absolute dry mass of rhizomes or not. These articles are marked with ND in the table. Both chemical synthesis and biosynthesis methods were applied for the production of salidroside and rosavin [33,39-42]. However, the maximum salidroside and rosavin obtained from these studies was limited and as low as $0.569 \mathrm{mg} \mathrm{mL}^{-1}$ and $1.107 \mathrm{mg} \mathrm{mL}^{-1}[32,33]$, respectively. On the other hand, in our study, a higher content of up to $51.0 \mathrm{mg} \mathrm{g}^{-1}$ of salidroside and $73.1 \mathrm{mg} \mathrm{g}^{-1}$ of rosavin was observed. Apparently, the freeze-drying method increased the concentration of all phenyletanes and phenylpropanoids compared with conventional drying at $70^{\circ} \mathrm{C}$. As far as we know, the content of salidroside observed in this study was the highest ever detected in Rhodiola spp. Although salidroside was the main investigated bioactive compound in clinical studies, treatment with this compound alone was less effective than with $R$. rosea extract, suggesting a synergistic effect with other compounds [43]. The highest significant correlation detected between rosavin and salidroside in this study showed a high quality and quantity in Norwegian $R$. rosea, which is suitable to meet the global pharmaceutical demand. 
Table 4. Comparison of the content of rosavin, salidroside, rosin, cinnamyl alcohol, and tyrosol in $R$. rosea reported in this study and in the literature. Values given are in $\mathrm{mg} \mathrm{g}^{-1}$.

\begin{tabular}{|c|c|c|c|c|c|c|}
\hline Origin of Plants & Rosavin & Salidroside & Rosin & Cinnamyl Alcohol & Tyrosol & Literature Reference \\
\hline Norway & 73.120 & 50.910 & 5.831 & 4.820 & 4.837 & This study ${ }^{1, D}$ \\
\hline Norway & 85.950 & 12.850 & 4.750 & 1.180 & 2.150 & {$[26]^{\mathrm{D}}$} \\
\hline China & ns & 11.100 & ns & ns & 2.200 & {$[44]^{\mathrm{D}}$} \\
\hline China & 0.650 & 11.140 & 3.580 & ns & 1.120 & [27] $\mathrm{ND}$ \\
\hline Finland & 0.790 & 0.280 & 0.120 & 0.080 & ns & {$[45]^{\mathrm{D}}$} \\
\hline Finland & 18.140 & 7.380 & ns & ns & ns & {$[46]^{\mathrm{D}}$} \\
\hline Lithuania & 3.688 & 1.352 & 1.603 & ns & $\mathrm{ns}$ & {$[47]^{\mathrm{D}}$} \\
\hline Mongolia & 18.700 & 13.100 & ns & 18.900 & ns & {$[37]^{\mathrm{D}}$} \\
\hline Poland & 27.900 & 4.000 & ns & 10.500 & $\mathrm{~ns}$ & {$[37]^{\mathrm{D}}$} \\
\hline Russia & 25.000 & 12.000 & ns & ns & ns & {$[48]^{\mathrm{D}}$} \\
\hline Russia & ns & ns & 1.000 & ns & ns & {$[49]^{\mathrm{ND}}$} \\
\hline Russia & 4.110 & 0.930 & 0.530 & 0.300 & ns & {$[45]^{\mathrm{D}}$} \\
\hline Russia & 0.562 & 1.624 & 2.574 & ns & ns & {$[47]^{\mathrm{D}}$} \\
\hline Sweden & 50.700 & 0.000 & ns & 15.600 & ns & $\left.{ }^{[37]}\right]^{\mathrm{D}}$ \\
\hline China & 0.027 & 0.271 & 0.180 & ns & 0.040 & {$[50]^{\mathrm{ND}}$} \\
\hline Pollen & 3.61 & 6.790 & ns & ns & 1.890 & {$[35]^{\mathrm{D}}$} \\
\hline Germany & 3.67 & 3.08 & 0.70 & 1.06 & 0.460 & {$[36]^{\mathrm{ND}}$} \\
\hline Bulgaria & 19.7 & 26.700 & 0.412 & ns & $\mathrm{ns}$ & [23] ND \\
\hline USA & 3.500 & 2.700 & 0.800 & ns & ns & [28] ND \\
\hline Norway & 18.10 & 17.70 & 2.00 & ns & 1.60 & [51] ${ }^{\mathrm{ND}}$ \\
\hline Bulgaria & $\mathrm{ns}$ & 14.6 & ns & ns & $\mathrm{ns}$ & {$[19]^{\mathrm{D}}$} \\
\hline Canada & 21.40 & 17.61 & 3.11 & ns & 2.82 & {$[52]^{\mathrm{D}}$} \\
\hline UK & 4.20 & 1.200 & ns & ns & ns & {$[53]^{\mathrm{D}}$} \\
\hline Austria & 2.70 & 27.30 & 1.50 & 8.80 & 18.4 & {$[54]^{\mathrm{D}}$} \\
\hline Norway & 3.63 & 21.19 & ns & 0.20 & 0.41 & [34] $\mathrm{D}$ \\
\hline Poland & 9.770 & 1.970 & 4.624 & ns & 0.381 & {$[14]^{\mathrm{D}}$} \\
\hline
\end{tabular}

${ }^{1}$ Results obtained using the freeze-drying method are presented in the table. ${ }^{\mathrm{D}}=$ concentrations were calculated for absolute dry mass of rhizomes; ${ }^{\mathrm{ND}}=$ not described (mostly commercially available products); $\mathrm{ns}=$ not studied.

The bioactive compounds' variability in $R$. rosea, between years, was reported from two to three, four to five, four to seven, and four to nine years $[14,35,46,55]$. To our knowledge, this is the first study that investigated the variability of active compounds in $R$. rosea from three to twelve years. Our 16-year-old $R$. rosea rhizomes showed increased content of these bioactive compounds. These results are in line with the results of Peschel et al. (2016) [56], who have studied 9-year-old rhizomes. Our results may support the hypothesis [26] that long-term vegetative propagation increases the accumulation of these bioactive compounds in $R$. rosea. Long-term vegetative propagation might lead to genetic adaptability and stability of these bioactive compounds in the absence of crossbreeding and seed propagation. The high content of salidroside and rosavin detected in the samples of $R$. rosea rhizomes from our germplasm collection in Norway, compared to the low quantity detected in other studies (Table 4), may be explained by the light of the longer days in spring and summer in northern latitudes that promote increased metabolite production. Furthermore, Galambosi et al. (2009) found that the content of total flavonoids of the Nordic R. rosea was higher than those originating from Central European countries [57].

The AFLP molecular data matrix of these seven R. rosea clones [21] was correlated with their chemical data. No significant association was found between the results from our previous AFLP analysis [21] and the chemical composition of the R. rosea clones in the current study. This result is in agreement with our previous study [26]. This might be because AFLP markers were limited to non-coding regions of the R. rosea genome. Thus, a further genomic study investigating genes responsible for the production of these bioactive compounds is required.

The various methods used to dry and extract the bioactive compounds of $R$. rosea have a large impact on the yield of phenyletanes and phenylpropanoids [36,58]. On the other hand, Zomborszki et al. (2019) reported that different drying methods did not affect the content of the bioactive compounds of R. rosea [59]. Our results supported the first hypothesis that freeze-drying of plant material before the 
extraction at low temperatures prevents degradation of bioactive compounds and ensures a high yield of bioactive compounds [58,60-62]. Long-term vegetative propagation and high genetic diversity [21] of $R$. rosea, together with the freeze-drying method, may explain the high content of the bioactive compounds observed in the current study.

The production of bioactive compounds in $R$. rosea is also influenced by environmental factors such as geographic origin [37,47,53], cultivated-wild and age [14,46], fertilization [20], plant parts and harvesting time $[14,53,54,56,63,64]$, growth factors such as day length and temperature [57], and plant gender $[46,56,65]$. Genetic factors strongly influence the production of bioactive compound contents in $R$. rosea $[21,27,32,40]$. However, $R$. rosea plants used in the present study were collected from various geographical locations in Norway and since 2001 were vegetatively propagated under the same environmental conditions in the Norwegian Institute for Bioeconomy Research (NIBIO) germplasm collection. Thus, the high chemo-diversity observed for different clones in this study can be explained by genetic factors rather than environmental influences. Further studies dealing with transcriptomic and gene expression are required.

\section{Materials and Methods}

\subsection{Materials and Reagents}

Seven clones (M1, M2, M3, M4, M5, M6, and M7) of $R$. rosea (Table 5) were selected from the Norwegian germplasm collection of Rhodiola rosea comprising 95 different clones collected in 2001 [26]. $R$. rosea clones were vegetatively propagated for the last 16 years at a field at the Norwegian Institute for Bioeconomy Research (NIBIO). The bioactive compounds (rosavin, salidroside, rosin, tyrosol, and cinnamyl alcohol) of these clones were previously analyzed and quantified [26].

Table 5. The seven clones of Rhodiola rosea from the Norwegian germplasm collection. For each clone, information about the regional ( $\mathrm{SW}=$ south-west, $\mathrm{ME}=$ mid-east, $N=$ north) and county origin, gender $(\mathrm{M}=$ male, $\mathrm{F}=$ female), and latitude and longitude is presented.

\begin{tabular}{|c|c|c|c|c|c|}
\hline Clone Id & Region & County & Gender & Latitude & Longitude \\
\hline M1 & SW & Rogland & $\mathrm{M}$ & $59^{\circ} 39^{\prime} \mathrm{N}$ & $0618^{\prime} \mathrm{E}$ \\
\hline M2 & $\mathrm{N}$ & Nordland & M & $68^{\circ} 05^{\prime} \mathrm{N}$ & $1538^{\prime} \mathrm{E}$ \\
\hline M3 & SW & $\begin{array}{l}\text { Sogn og } \\
\text { Fjordane }\end{array}$ & M & $61^{\circ} 10^{\prime} \mathrm{N}$ & $0601^{\prime} \mathrm{E}$ \\
\hline M4 & $\mathrm{N}$ & Finnmark & M & $70^{\circ} 36^{\prime} \mathrm{N}$ & $2700^{\prime} \mathrm{E}$ \\
\hline M5 & ME & Sør-Trondelag & $\mathrm{M}$ & $63^{\circ} 09^{\prime} \mathrm{N}$ & $1139^{\prime} \mathrm{E}$ \\
\hline M6 & SW & $\begin{array}{l}\text { Møre og } \\
\text { Romsdal }\end{array}$ & M & $62^{\circ} 25^{\prime} \mathrm{N}$ & $0759^{\prime} \mathrm{E}$ \\
\hline M7 & $\mathrm{N}$ & Finnmark & $\mathrm{F}$ & $70^{\circ} 37^{\prime} \mathrm{N}$ & $2700^{\prime} \mathrm{E}$ \\
\hline
\end{tabular}

In October 2017, 100-150 g of rhizomes of each $R$. rosea clone was collected, washed, and sliced, and two separate methods were used to dry these rhizomes: (i) the samples were dried for $14 \mathrm{~h}$ at $70{ }^{\circ} \mathrm{C}$ and then stored at room temperature; (ii) the samples were immediately frozen in liquid nitrogen and then freeze-dried at $-130{ }^{\circ} \mathrm{C}$ for $14 \mathrm{~h}$ in $50 \mathrm{~mL}$ tubes and then stored at $-20^{\circ} \mathrm{C}$ until analysis. For each drying method, the fresh weight, dry weight, and the percentage of loss of water (loss of moisture) were determined gravimetrically according to European Pharmacopoeia recommendations, and the results are presented in Table 1 . R. rosea rhizomes were freeze-dried using a Labconco freeze-dryer (Millrock Technology Inc. Kingston, NY, USA).

\subsection{Extraction and HPLC Analysis}

About $1.0 \mathrm{~g}$ of rhizomes was extracted with $50 \mathrm{~mL}$ of $70 \%$ ethanol in an ultrasonic bath for $30 \mathrm{~min}$ at room temperature. After filtration, plant material was twice extracted using additional amounts $(25 \mathrm{~mL})$ of $70 \%$ ethanol at the same conditions. Extracts were combined, filtered into a $100 \mathrm{~mL}$ 
volumetric flask, and added to $70 \%$ ethanol; $3 \mathrm{~mL}$ was taken for HPLC-analysis. HPLC analysis was performed as described previously [26]. The reference standards of salidroside, tyrosol, rosavin, rosin, and cinnamyl alcohol were purchased from Sigma-Aldrich, (St Louis, MO, USA). The limit of quantification (LOQ) for the reference substances was $0.25,0.25,0.25,0.2$, and $0.25-\mu \mathrm{g} \mathrm{mL} \mathrm{m}^{-1}$ for salidroside, tyrosol, rosavin, rosin, and cinnamyl alcohol, respectively. The analyses were performed at the same laboratory in St. Petersburg Institute of Pharmacy, Russia, as previously described [26]. The concentrations of salidroside, tyrosol, rosavin, rosin, and cinnamyl alcohol were calculated for absolute dry mass of rhizomes. All chemical analyses were performed in triplicate for each sample to ensure reproducibility, and the means were compared by Fisher's least significant difference (LSD) test.

\subsection{Statistical Analyses}

\subsubsection{Correlation Analyses}

Before analyses, data sets were checked for normality of their distributions. All data were normally distributed and thus were analyzed in their raw form using the PROC MIXED function of SAS (SAS, 2002-2003) and including Tukey's adjustment for multiple comparisons. Stated differences between observations were declared when $p<0.05$. Pearson product moment correlations between the concentration of each bioactive compound and the concentrations of the other four bioactive compounds were calculated by the PROC CORR function of SAS (SAS, 2002-2003).

\subsubsection{Association Analysis}

Association between AFLP markers [21] and the production of bioactive compounds of $R$. rosea clones in the present study was estimated through stepwise multiple regression analysis, where each chemical compound was treated as a dependent variable while the AFLP marker was treated as an independent variable as described by Virk et al. (1996) [66]. To select independent variables for the regression equation, F-values with 0.045 and 0.099 probability were used to enter and remove, respectively, as suggested by Roy and Bargmann (1957) [67] and Affifi and Clark (1990) [68]. The analysis was performed using the MINITAB program. Only results obtained using the freeze-drying method were compared to our previous study [26].

\section{Conclusions}

To the best of our knowledge, this is the first study in which the production of the major phenyletanes and phenylpropanoids rosavin, salidroside, rosin, cinnamyl alcohol, and tyrosol by rhizomes of seven clones of $R$. rosea vegetatively propagated for 16 years is reported. We assume that the high chemo-diversity observed for different clones in this study can be explained by genetic factors rather than environmental influences. Further studies dealing with transcriptomic and gene expression are required to confirm this hypothesis. The freeze-drying method increased the concentration of all phenyletanes and phenylpropanoids in rhizomes compared with conventional drying at $70^{\circ} \mathrm{C}$. Long-term vegetative propagation and high genetic diversity of $R$. rosea, together with the freeze-drying method, may have led to the high content of the bioactive compounds observed in the current study.

Author Contributions: Conceptualization, A.E. Data curation, V.M.K.; Validation, A.E., and V.M.K.; Investigation, A.E., V.M.K.; Methodology, A.E., A.N.S., M.T., V.M.K. and O.N.P.; Project administration, A.E.; Resources, A.E. Supervision, A.E., and A.N.S.; Visualization, V.M.K.; Writing-original draft, A.E.; A.N.S., O.N.P. Writing一review and editing, A.E., A.N.S., M.T., V.M.K. and O.N.P. All authors have read and agreed to the published version of the manuscript.

Funding: The study was funded by Norwegian Institute of Bioeconomy Research.

Acknowledgments: The Norwegian Institute for Bioeconomy Research (NIBIO) has financed this work. The authors would like to thank Nils Vagstad, Bjørn Langerud, Arne Hermansen, Hans Geir Eiken, and Valery Makarov for their interest and support to the project. The authors would also like to thank Erling Fjelldal for the assistance in collecting the $R$. rosea materials.

Conflicts of Interest: The authors declare no conflict of interest. 


\section{References}

1. Kelly, G. Rhodiola rosea: A possible plant adaptogen. Altern. Med. Rev. 2001, 6, 293-302. [PubMed]

2. Ming, D.S.; Hillhouse, B.J.; Guns, E.S.; Eberding, A.; Xie, S.; Vimalanathan, S.; Towers, G.N. Bioactive compounds from Rhodiola rosea (Crassulaceae). Phytother. Res. 2005, 19, 740-743. [CrossRef] [PubMed]

3. Panossian, A.; Wikman, G.; Sarris, J. Rosenroot (Rhodiola Rosea): Traditional use, chemical composition, pharmacology and clinical efficacy. Phytomedicine 2010, 17, 481-493. [CrossRef]

4. Panossian, A. Understanding adaptogenic activity: Specificity of the pharmacological action of adaptogens and other phytochemicals. Ann. N. Y. Acad. Sci. 2017, 1401, 49-64. [CrossRef] [PubMed]

5. Bykov, V.; Zapesochnaya, G.; Kurkin, V. Traditional and biotechnological aspects of obtaining medicinal preparations from Rhodiola Rosea L. (A review). Pharm. Chem. J. 1999, 33, 29-40. [CrossRef]

6. Fägringar, M.B. Växter som berör oss (Beauty: Herbs that Touch Us); Berntssons: Östersund, Sweden, 1992; pp. 66-67. (In Swedish)

7. Zhong, Z.; Han, J.; Zhang, J.; Xiao, Q.; Hu, J.; Chen, L. Pharmacological activities, mechanisms of action, and safety of salidroside in the central nervous system. Drug Des. Dev. 2018, 12, 1479-1489. [CrossRef]

8. Kosakowska, O.; Bączek, K.; Przybył, J.L.; Pióro-Jabrucka, E.; Czupa, W.; Synowiec, A.; Gniewosz, M.; Costa, R.; Mondello, L.; Węglarz, Z. Antioxidant and antibacterial activity of roseroot (Rhodiola rosea L.) dry extracts. Molecules 2018, 23, 1767. [CrossRef]

9. Pu, W.-1.; Zhang, M.-Y.; Bai, R.-Y.; Sun, L.-K.; Li, W.-H.; Yu, Y.-L.; Zhang, Y.; Song, L.; Wang, Z.-X.; Peng, Y.-F. Anti-inflammatory effects of Rhodiola rosea L.: A review. Biomed. Pharm. 2020, 121, 109552. [CrossRef]

10. Xin, X.; Yao, D.; Zhang, K.; Han, S.; Liu, D.; Wang, H.; Liu, X.; Li, G.; Huang, J.; Wang, J. Protective effects of rosavin on bleomycin-induced pulmonary fibrosis via suppressing fibrotic and inflammatory signaling pathways in mice. Biomed. Pharm. 2019, 115, 108870. [CrossRef]

11. Amsterdam, J.D.; Panossian, A.G. Rhodiola rosea L. as a putative botanical antidepressant. Phytomedicine 2016, 23, 770-783. [CrossRef]

12. Panossian, A.; Seo, E.J.; Efferth, T. Effects of anti-inflammatory and adaptogenic herbal extracts on gene expression of eicosanoids signaling pathways in isolated brain cells. Phytomedicine 2019, 60, 152881. [CrossRef] [PubMed]

13. Xie, H.; Shen, C.-Y.; Jiang, J.-G. The sources of salidroside and its targeting for multiple chronic diseases. J. Funct. Foods 2019, 64, 103648. [CrossRef]

14. Kolodziej, B.; Sugier, D. Influence of plants age on the chemical composition of roseroot (Rhodiola rosea L.). Acta Sci. Pol. Hortorum Cultus 2013, 12, 147-160.

15. Grech-Baran, M.; Syklowska-Baranek, K.; Pietrosiuk, A. Approaches of Rhodiola kirilowii and Rhodiola rosea field cultivation in Poland and their potential health benefits. Ann. Agric. Environ. Med. 2015, 22, 281-285. [CrossRef] [PubMed]

16. Kotiranta, H.; Uotila, P.; Sulkava, S.; Peltonnen, S.-L. (Eds.) Red Data Book of East Fennoscandia; Ministry of Environment; Finnish Environment Institute \& Botanical Museum; Finnish Museum of Natural History: Helsinki, Finland, 1998; p. 351.

17. Lange, D. Europe's Medicinal and Aromatic Plants: Their Use, Trade and Conservation; Traffic International: Cambridge, UK, 1998.

18. Dines, T.D.; Jones, R.A.; Leach, S.J.; McKean, D.R.; Pearman, D.A.; Preston, C.D.; Rumsey, F.J.; Taylor, I. The Vascular Plant Red Data List for Great Britain; Species Status 7; Cheffings, C.M., Farrell, L., Eds.; Joint Nature Conservation Committee: Peterborough, UK, 2015. Available online: https://hub.jncc.gov.uk/assets/ cc1e96f8-b105-4dd0-bd87-4a4f60449907 (accessed on 1 June 2020).

19. Platikanov, S.; Evstatieva, L. Introduction of wild golden root (Rhodiola rosea L.) as a potential economic crop in Bulgaria. Econ. Bot. 2008, 62, 621-627. [CrossRef]

20. Galambosi, B. Demand and availability of Rhodiola rosea raw material. Frontis 2006, 17, 223-236.

21. Elameen, A.; Klemsdal, S.S.; Dragland, S.; Fjellheim, S.; Rognli, O.A. Genetic diversity in a germplasm collection of roseroot (Rhodiola rosea) in Norway studied by AFLP. Biochem. Syst. Ecol. 2008, 36, 706-715. [CrossRef]

22. Shikov, A.N.; Kosman, V.M.; Flissyuk, E.V.; Smekhova, I.E.; Elameen, A.; Pozharitskaya, O.N. Natural deep eutectic solvents for the extraction of phenyletanes and phenylpropanoids of Rhodiola rosea L. Molecules 2020, 25, 1826. [CrossRef] 
23. Marchev, A.S.; Dinkova-Kostova, A.T.; György, Z.; Mirmazloum, I.; Aneva, I.Y.; Georgiev, M.I. Rhodiola rosea L.: From golden root to green cell factories. Phytochem. Rev. 2016, 15, 515-536. [CrossRef]

24. Guo, C.; Li, Y.; Zhang, R.; Zhang, Y.; Zhao, J.; Yao, J.; Sun, J.; Dong, J.; Liao, L. protective effect of salidroside against diabetic kidney disease through inhibiting BIM-mediated apoptosis of proximal renal tubular cells in rats. Front. Pharmacol. 2018, 9, 1433. [CrossRef]

25. Hao, X.; Yuan, J.; Dong, H. Salidroside prevents diabetes-induced cognitive impairment via regulating the Rho pathway. Mol. Med. Rep. 2019, 19, 678-684. [CrossRef] [PubMed]

26. Elameen, A.; Dragland, S.; Klemsdal, S.S. Bioactive compounds produced by clones of Rhodiola rosea maintained in the Norwegian germplasm collection. Die Pharm. An Int. J. Pharm. Sci. 2010, 65, 618-623.

27. Ma, C.; Wang, H.; Gu, X.; Hu, L. Large-scale preparative isolation of rosavin from Rhodiola rosea via Ion liquids MAE and subsequent flash adsorption chromatography. Sep. Sci. Technol. 2012, 47, 1821-1827. [CrossRef]

28. Ganzera, M.; Yayla, Y.; Khan, I.A. Analysis of the marker compounds of Rhodiola rosea L. (golden root) by reversed phase high performance liquid chromatography. Chem. Pharm. Bull. (Tokyo) 2001, 49, 465-467. [CrossRef]

29. Li, H.; Chen, C. Inhibition of autophagy enhances synergistic effects of salidroside and anti-tumor agents against colorectal cancer. BMC Complement Altern. Med. 2017, 17, 538. [CrossRef] [PubMed]

30. Shikov, A.N.; Pozharitskaya, O.N.; Makarov, V.G.; Wagner, H.; Verpoorte, R.; Heinrich, M. Medicinal plants of the Russian Pharmacopoeia; their history and applications. J. Ethnopharmacol. 2014, 154, 481-536. [CrossRef]

31. Bejar, E.; Upton, R.; John, H. Adulteration of Rhodiola (Rhodiola rosea) rhizome and root and extracts. Bot Adulterants Bull. 2017, 1-8. Available online: www.botanicaladulterants.org (accessed on 20 May 2020).

32. Yu, H.-S.; Ma, L.-Q.; Zhang, J.-X.; Shi, G.-L.; Hu, Y.-H.; Wang, Y.-N. Characterization of glycosyltransferases responsible for salidroside biosynthesis in Rhodiola sachalinensis. Phytochemistry 2011, 72, 862-870. [CrossRef]

33. Bi, H.; Wang, S.; Zhou, W.; Zhuang, Y.; Liu, T. Producing Gram-scale unnatural rosavin analogues from glucose by engineered Escherichia coli. ACS Synth. Biol. 2019, 8, 1931-1940. [CrossRef]

34. Hellum, B.H.; Tosse, A.; Hoybakk, K.; Thomsen, M.; Rohloff, J.; Nilsen, O.G. Potent in vitro inhibition of CYP3A4 and P-glycoprotein by Rhodiola rosea. Planta Med. 2010, 76, 331-338. [CrossRef]

35. Adamczak, A.; Buchwald, W.; Gryszczynska, A. Biometric features and content of phenolic compounds of roseroot (Rhodiola rosea L.). Acta Soc. Bot. Pol. 2016, 85, 3500. [CrossRef]

36. Dimpfel, W.; Schombert, L.; Panossian, A.G. Assessing the quality and potential efficacy of commercial extracts of Rhodiola rosea L. by analyzing the salidroside and rosavin content and the electrophysiological activity in hippocampal long-term potentiation, a synaptic model of memory. Front. Pharmacol. 2018, 9, 425. [CrossRef] [PubMed]

37. Wiedenfeld, H.; Dumaa, M.; Malinowski, M.; Furmanowa, M.; Narantuya, S. Phytochemical and analytical studies of extracts from Rhodiola rosea and Rhodiola quadrifida. Pharmazie 2007, 62, 308-311. [PubMed]

38. Booker, A.; Jalil, B.; Frommenwiler, D.; Reich, E.; Zhai, L.; Kulic, Z.; Heinrich, M. The authenticity and quality of Rhodiola rosea products. Phytomedicine 2016, 23, 754-762. [CrossRef] [PubMed]

39. Xue, F.; Yang, M.; Ma, L. Microbial synthesis of salidroside. Sheng Wu Gong Cheng Xue Bao 2019, 35, 1184-1192. [PubMed]

40. Bai, Y.; Bi, H.; Zhuang, Y.; Liu, C.; Cai, T.; Liu, X.; Zhang, X.; Liu, T.; Ma, Y. Production of salidroside in metabolically engineered Escherichia coli. Sci. Rep. 2014, 4, 6640. [CrossRef]

41. Xue, F.; Guo, H.; Hu, Y.; Liu, R.; Huang, L.; Lv, H.; Liu, C.; Yang, M.; Ma, L. Expression of codon-optimized plant glycosyltransferase UGT72B14 in Escherichia coli enhances salidroside production. BioMed Res. Int. 2016, 2016, 9845927. [CrossRef]

42. Patov, S.A.; Punegov, V.V.; Kuchin, A.V. Synthesis of the Rhodiola rosea glycoside rosavin. Chem. Nat. Compd. 2006, 42, 397-399. [CrossRef]

43. Lin, S.S.C.; Chin, L.W.; Chao, P.C.; Lai, Y.Y.; Lin, L.Y.; Chou, M.Y.; Chou, M.C.; Wei, J.C.C.; Yang, C.C. In vivo Th1 and Th2 cytokine modulation effects of Rhodiola rosea standardised solution and its major constituent, salidroside. Phytother. Res. 2011, 25, 1604-1611.

44. Linh, P.T.; Kim, Y.H.; Hong, S.P.; Jian, J.J.; Kang, J.S. Quantitative determination of salidroside and tyrosol from the underground part of Rhodiola rosea by high performance liquid chromatography. Arch. Pharm. Res. 2000, 23, 349-352. [CrossRef] 
45. Makarov, V.; Zenkevich, I.; Shikov, A.; Pimenov, A.; Pozharitskaya, O.; Ivanova, S.; Galambosi, B. Comparative analysis of Rhodiola rosea of Scandinavian and Russian origin. In Proceedings of the Congress: Phytopharm 2003. Actual Problems of Creation of New Medicinal Preparations of Natural Origin, St. Petersburg-Pushkin, Russia, 3-5 July 2003; pp. 570-574.

46. Galambosi, B.; Galambosi, Z.; Uusitalo, M.; Heinonen, A. Effects of plant sex on the biomass production and secondary metabolites in roseroot (Rhodiola rosea L.) from the aspect of cultivation. Z. Für Arznei Gewürzpflanzen 2009, 14, 114-121.

47. Kučinskaitè, A.; Pobłocka-Olech, L.; Krauze-Baranowska, M.; Sznitowska, M.; Savickas, A.; Briedis, V. Evaluation of biologically active compounds in roots and rhizomes of Rhodiola rosea L. cultivated in Lithuania. Medicina 2007, 43, 487-494. [CrossRef] [PubMed]

48. Kurkin, V.; Zapesochnaya, G. The chemical-composition and pharmacological properties of rhodiola plants. Pharm. Chem. J. 1986, 20, 1231-1244.

49. Kurkin, V.; Zapesochnaya, G.; Nukhimovsky, E.; Klimakhin, G. Chemical-composition of rhizomes of Mongolian Rhodiola-rosea L population introduced into districts near Moscow. Pharm. Chem. J. 1988, 22, 324-326.

50. Liu, Z.; Liu, Y.; Liu, C.; Song, Z.; Li, Q.; Zha, Q.; Lu, C.; Wang, C.; Ning, Z.; Zhang, Y. The chemotaxonomic classification of Rhodiola plants and its correlation with morphological characteristics and genetic taxonomy. Chem. Cent. J. 2013, 7, 118. [CrossRef]

51. Thu, O.K.; Nilsen, O.G.; Hellum, B. In vitro inhibition of cytochrome P-450 activities and quantification of constituents in a selection of commercial Rhodiola rosea products. Pharm. Biol. 2016, 54, 3249-3256. [CrossRef]

52. Saunders, D.; Poppleton, D.; Struchkov, A.; Ireland, R. Analysis of five bioactive compounds from naturally occurring Rhodiola rosea in eastern Canada. Can. J. Plant Sci. 2014, 94, 741-748. [CrossRef]

53. Peschel, W.; Prieto, J.M.; Karkour, C.; Williamson, E.M. Effect of provenance, plant part and processing on extract profiles from cultivated European Rhodiola rosea L. for medicinal use. Phytochemistry 2013, 86, 92-102. [CrossRef]

54. Mirmazloum, I.; Ladányi, M.; György, Z. Changes in the content of the glycosides, aglycons and their possible precursors of Rhodiola rosea during the vegetation period. Nat. Prod. Commun. 2015, 10, 1413-1416. [CrossRef]

55. Peschel, W.; Kump, A.; Zomborszki, Z.P.; Pfosser, M.; Kainz, W.; Csupor, D. Phenylpropenoid content in high-altitude cultivated Rhodiola rosea L. provenances according to plant part, harvest season and age. Ind. Crop. Prod. 2018, 111, 446-456. [CrossRef]

56. Peschel, W.; Kump, A.; Horvath, A.; Csupor, D. Age and harvest season affect the phenylpropenoid content in cultivated European Rhodiola rosea L. Ind. Crop. Prod. 2016, 83, 787-802. [CrossRef]

57. Galambosi, B.; Galambosi, Z.; Varga, E.; Hajdu, Z.; Telek, E. Cultivation methods, root yield and flavonoid content of roseroot (Rhodiola rosea L.) cultivated in Finland. In Proceedings of the Book of abstracts of the IV International Conference on Cultivation, Harvesting and Processing of Medicinal Herbs, L'ubovnianske Kúpele, Slovakia, 8-11 June 1999.

58. Alperth, F.; Turek, I.; Weiss, S.; Vogt, D.; Bucar, F. Qualitative and quantitative analysis of different Rhodiola rosea rhizome extracts by UHPLC-DAD-ESI-MSn. Sci. Pharm. 2019, 87, 8. [CrossRef]

59. Zomborszki, Z.P.; Kusz, N.; Csupor, D.; Peschel, W. Rhodiosin and herbacetin in Rhodiola rosea preparations: Additional markers for quality control? Pharm. Biol. 2019, 57, 295-305. [CrossRef] [PubMed]

60. Hosein, F. Isolation of high quality RNA from seeds and tubers of the Mexican yam bean (Pachyrhizus erosus). Plant Mol. Biol. Rep. 2001, 19, 65. [CrossRef]

61. Reyes, A.; Mahn, A.; Cares, V. Analysis of dried onions in a hybrid solar dryer, freeze dryer and tunnel dryer. Chem. Eng. Trans. 2015, 43, 139-144.

62. Garcia-Baldenegro, C.V.; Vargas-Arispuro, I.; Islas-Osuna, M.; Rivera-Dominguez, M.; Aispuro-Hernandez, E.; Martinez-Tellez, M.A. Total RNA quality of lyophilized and cryopreserved dormant grapevine buds. Electron. J. Biotechnol. 2015, 18, 134-137. [CrossRef]

63. Thomsen, M.G.; Galambosi, B.; Galambosi, Z.; Uusitalo, M.; Mordal, R.; Heinonen, A. Harvest time and drying temperature effect on secondary metabolites in Rhodiola rosea. Acta Hortic. 2012, 955, 243-252. [CrossRef]

64. Ioset, K.N.; Nyberg, N.T.; Van Diermen, D.; Malnoe, P.; Hostettmann, K.; Shikov, A.N.; Jaroszewski, J.W. Metabolic profiling of Rhodiola rosea rhizomes by ${ }^{1} \mathrm{H}$ NMR spectroscopy. Phytochem. Anal. 2011, 22, 158-165. [CrossRef] 
65. Weglarz, Z.; Roslon, W. Developmental and chemical variability of female and male forms of nettle Urtica dioica L. In Proceedings of the XXV International Horticultural Congress, Part 13: New and Specialized Crops and Products, Botanic Gardens and Human-Horticulture Relationship. ISHS Acta Hortic. 1998, 523, 75-80.

66. Virk, P.S.; FordLloyd, B.V.; Jackson, M.T.; Pooni, H.S.; Clemeno, T.P.; Newbury, H.J. Predicting quantitative variation within rice germplasm using molecular markers. Heredity 1996, 76, 296-304. [CrossRef]

67. Roy, S.N.; Bargmann, R.E. Tests of Multiple Independence and the Associated Confidence-Bounds; Mimeograph Series No. 175; North Carolina Institute of Statistics: Chapel Hill, NC, USA, 1957.

68. Afifi, A.; Clark, V. Computer-Aided Multivariate Analysis, 2nd ed.; Van Nostrand Reinhold Co.: New York, NY, USA, 1990; p. 503.

Sample Availability: Samples of the compounds are available from the authors.

(C) 2020 by the authors. Licensee MDPI, Basel, Switzerland. This article is an open access article distributed under the terms and conditions of the Creative Commons Attribution (CC BY) license (http://creativecommons.org/licenses/by/4.0/). 